\title{
In situ soft X-ray absorption spectroscopy investigation of electrochemical corrosion of copper in aqueous $\mathrm{NaHCO}_{3}$ solution
}

\author{
Peng Jiang, ${ }^{\mathrm{a}, \mathrm{b}, 1}$ Jeng-Lung Chen, ${ }^{\mathrm{c}, \mathrm{d}, 1}$ Ferenc Borondics, ${ }^{\mathrm{e}}$ Per-Anders Glans, ${ }^{\mathrm{c}}$ Mark W. West, ${ }^{\mathrm{a}}$ \\ Ching-Lin Chang, ${ }^{\mathrm{d}}$ Miquel Salmeron, ${ }^{\mathrm{a}, \mathrm{b}, *}$, and Jinghua Guo, ${ }^{\mathrm{c}, *}$
}

\footnotetext{
${ }^{a}$ Materials Sciences Division, Lawrence Berkeley National Laboratory, Berkeley, California 94720 USA

${ }^{\mathrm{b}}$ Department of Materials Science and Engineering, University of California, Berkeley, California 94720 USA

${ }^{c}$ Advanced Light Source, Lawrence Berkeley National Laboratory, Berkeley, California 94720 USA

${ }^{\mathrm{d}}$ Department of Physics, Tamkang University, Tamsui, Taiwan

${ }^{\mathrm{e}}$ Chemical Sciences Division, Lawrence Berkeley National Laboratory, Berkeley, California 94720 USA

${ }^{1}$ These authors contributed equally to this work.
}

\section{Corresponding authors:}

* Miquel Salmeron

Materials Sciences Division, Mail Stop 67R2206

Lawrence Berkeley National Laboratory

1 Cyclotron Road, Berkeley, CA 94720 USA

Phone: +1-510-486-6230

FAX: $+1-510-486-7268$

E-mail: MBSalmeron@lbl.gov,

* Jinghua Guo

Advanced Light Source Division, Mail Stop 6R2100

Lawrence Berkeley National Laboratory

1 Cyclotron Road, Berkeley, CA 94720, USA

Phone: +1-510-495-2230

FAX: +1-510-495-2067

E-mail: JGuo@lbl.gov

\begin{abstract}
A novel electrochemical setup has been developed for soft x-ray absorption studies of the electronic structure of electrode materials during electrochemical cycling. In this communication we illustrate the operation of the cell with a study of the corrosion behavior of copper in aqueous $\mathrm{NaHCO}_{3}$ solution via the electrochemically induced changes of its electronic structure. This development opens the
\end{abstract}


way for in situ investigations of electrochemical processes, photovoltaics, batteries, fuel cells, water splitting, corrosion, electrodeposition, and a variety of important biological processes.

\section{Introduction}

Understanding the mechanism of electrochemical reactions is important from the basic science point of view, as well as for the development of electrochemical applications, such as batteries, solar and fuel cells, etc [1-6]. It is also important in studies of the corrosion and wear of copper brushes in electrical motors [7]. This is best accomplished by the combination of electrochemical measurements with spectroscopic techniques. However, ex situ characterization methods suffer from a number of experimental limitations. For instance, transferring samples from one instrument to another can easily result in chemical changes in the state of the sample and introduce artifacts. In order to avoid the unwanted change of composition and electronic structure, in situ techniques are required. Several in situ techniques have been used to investigate electrochemical processes, including scanning probe microscopy, x-ray diffraction, infrared reflection absorption spectroscopy, surface-enhanced Raman spectroscopy, sum frequency generation, etc [8,9]. However, these techniques have limited capabilities in providing direct electronic structure information, which is the key for monitoring changes in the oxidation state.

In this communication we demonstrate a novel liquid flow cell for in situ soft x-ray absorption studies under controlled electrochemical conditions. This setup allow the real time monitoring of the element specific electronic structure changes of a system at all stages of the electrochemical cycle. Using this technique we have investigated the oxidation of $\mathrm{Cu}$ in $\mathrm{NaHCO}_{3}$ solution under controlled electrochemical conditions.

\section{Experimental}

X-ray absorption spectroscopy (XAS) is an element specific technique with the capability to determine the unoccupied density of states, and thus to provide the oxidation state of the material [10]. In the last decades, due to the relatively simple instrumentation, XAS using hard x-rays has been widely utilized to carry out in situ investigation of important electrochemical processes [11-13]. Nevertheless, the electronic information about the $3 \mathrm{~d}$ electrons in transition metals and their compounds is inaccessible from $\mathrm{K}$-edge spectra due to dipole selection rule. The sharp L-edge in the soft $\mathrm{x}$-ray range on the other hand, can provide more valuable chemical information in this aspect. Moreover the K-edge of light elements is also accessible with soft $\mathrm{x}$-rays. The large absorption cross-section of most gases and liquids in this energy range requires the use of UHV instrumentation. However by using ultrathin membranes to separate the 
samples from the UHV environment, soft x-rays can be used for studies under real conditions, such as high-pressure gas and liquid environments [14-21].

Several groups have investigated the electronic structure of liquid water by using such in situ XAS techniques [16-18]. Recently, the changes of electronic structure of $\mathrm{Cu}$ thin films in various aqueous solutions have also been studied in situ. However, due to the lack of potential control, these studies were limited to "static" electrochemical conditions [19]. In situ electrochemical reactions have also been studied by scanning transmission x-ray microscopy, where liquid cells without the capability of flowing the electrolyte solution were used [20,21]. These setups suffered from the formation of gas bubbles during electrochemical reactions and the difficult exchange of electrolytes [17,20].

Our experiments were performed at beamline 7.0.1 of the Advanced Light Source in Berkeley, California, USA. The schematic design of the cell is shown in Figure 1. The body (Fig 1c) of the cell was made of a UHV compatible and chemically inert polymer (polyether ether ketone, PEEK). A thin ( 100 $\mathrm{nm}$ ) silicon nitride $\left(\mathrm{Si}_{3} \mathrm{~N}_{4}\right)$ membrane, held by a $\mathrm{Si}$ frame (a, in Fig 1), separated the cell chamber from the UHV environment, with base pressure of $5 \times 10^{-9}$ Torr during measurements. A thin Cu film ( $\left.300 \mathrm{~nm}\right)$ with $5 \mathrm{~nm}$ adhesive $\mathrm{Cr}$ layer was thermally deposited on the cell side of the membrane and used as working electrode $\left(b^{1}\right.$, Fig 1$)$ in a three-electrode setup. The thickness of the $\mathrm{Cu}$ film was selected to allow the penetration of the incident $\mathrm{x}$-rays and the escape of the fluorescence photons. A Pt wire as the counter electrode $\left(b^{3}\right.$, Fig 1) and a $\mathrm{Ag}$ wire as pseudo-reference electrode $\left(b^{2}\right.$, Fig 1$)$ were inserted in the cell body through small holes on the sides. The electrolyte was flowing through two holes located at the backside of the body. The body was attached to a support tube, which was fixed on an XYZ adjustable manipulator. The potential was controlled by a VersaSTAT4 (Princeton Applied Research) potentiostat. XAS spectra were recorded in the total fluorescence yield mode using a channeltron detector and the intensities were normalized to a reference signal recorded simultaneously on a gold mesh. The energy scale was calibrated by using metallic $\mathrm{Cu}$ foil as reference.

\section{Results and Discussion}

Figure 2a) shows the cyclic voltammetric curve of the $\mathrm{Cu}$ thin film at a scan rate of $0.02 \mathrm{~V} / \mathrm{s}$ in $0.1 \mathrm{M}$ $\mathrm{NaHCO}_{3}$ solution in this cell setup. The characteristic oxidation and reduction peaks of copper are clearly observable. Anodic peaks I and II correspond to the formation of $\mathrm{Cu}^{+}$and $\mathrm{Cu}^{2+}$, respectively. Cathodic peaks II and I are related to the reduction of $\mathrm{Cu}^{2+}$ to $\mathrm{Cu}^{+}$and $\mathrm{Cu}^{+}$to $\mathrm{Cu}^{0}$, respectively. These observations and assignments are consistent with previous reports [22,23].

$\mathrm{Cu} \mathrm{L} \mathrm{L}_{2,3}$-edge XAS of $\mathrm{Cu}$ thin film on $\mathrm{Si}_{3} \mathrm{~N}_{4}$ membrane before contacting any solution is shown in Fig. 2b) (2). The main component can be assigned to the $\mathrm{L}_{3}$ edge $(932.7 \mathrm{eV})$ of metallic $\mathrm{Cu}$, consistent with the metallic $\mathrm{Cu}$ reference sample (Fig. 2b, curve (1)) [19,24,25]. Except the main peak, there is one 
additional peak at the lower photon energy side $(930 \mathrm{eV})$, which can be ascribed to $\mathrm{Cu}^{2+}$ species. These features indicate that a thin oxidized layer is formed on the surface of the evaporated $\mathrm{Cu}$ film due to oxidation in air during transfer. These observations indicate the importance of in situ measurements for investigations of electrochemical reactions in order to avoid introducing artifacts and misinterpreting experimental data.

The in situ XAS spectra acquired during electrochemical reactions are presented in Fig. 2b) (3) and (4). The intensity of the $\mathrm{Cu}^{2+}$ peak $(930 \mathrm{eV})$ increased significantly when the potential was set to a nominal value of $0.2 \mathrm{~V}$. In contrast, the $\mathrm{Cu}^{2+}$ oxidation peak disappears when reduction occurs at nominally $-0.9 \mathrm{~V}$. By keeping the potential constant, we could follow the oxidation and reduction kinetics of the $\mathrm{Cu}$ thin film. In Fig. 3 (a), the XAS intensity of $\mathrm{Cu}^{2+}$ peak increases gradually during oxidation process, while the intensity of $\mathrm{Cu}^{2+}$ peak decreases during reduction, as shown in Fig. 3 (b). The oxidation and reduction processes could be repeated several times, until the thin $\mathrm{Cu}$ film was completely dissolved [22,23].

\section{Conclusions}

In summary, we have shown how in situ soft x-ray absorption spectroscopy can be performed under electrochemical control. We have used the technique to successfully study the corrosion behavior of $\mathrm{Cu}$ in aqueous $\mathrm{NaHCO}_{3}$ solution. Our novel technique combines the capabilities of element specific soft x-ray absorption spectroscopy and electrochemistry, thus opening the way for in situ investigations of electrochemical applications in photovoltaics, batteries, fuel cells, water splitting, corrosion, electrodeposition, and a variety of important biological processes.

\section{Acknowledgements}

This work was supported by the Office of Naval Research under Contract No. N00014-08-1-0732. The work at the ALS was supported by the Director, Office of Science, Office of Basic Energy Sciences, Chemical Sciences, Geosciences, and Biosciences Division, of the Department of Energy under Contract No. DE-AC02-05CH11231. The authors thank Dr. Hendrik Bluhm, Dr. Zhi Liu and Dr. Wanli Yang for their helpful discussions.

\section{References}

[1] M. Armand, J. M. Tarascon, Nature 451 (2008) 652.

[2] M. W. Kanan, D. G. Nocera, Science 321 (2008) 1072.

[3] M. Lefèvre, E. Proietti, F. Jaouen, J. P. Dodelet, Science 324 (2009) 71.

[4] J. Yano, J. Kern, K. Sauer, M. J. Latimer, Y. Pushkar, J. Biesiadka, B. Loll, W. Saenger, J. Messinger, A. Zouni, V. K. Yachandra, Science 314 (2006) 821. 
[5] F. U. Renner, A. Stierle, H. Dosch, D. M. Kolb, T. L. Lee, J. Zegenhagen, Nature 439 (2006) 707.

[6] J. A. Switzer, H. M. Kothari, P. Poizot, S. Nakanishi, E. W. Bohannan, Nature 425 (2003) 490.

[7] P. G. Slade, Electrical Contacts: Principles and Applications; Marcel Dekker: New York, 1999.

[8] A. J. Bard, L. R. Faulkner, Electrochemical methods: Fundamentals and Applications; Wiley, 2001.

[9] M. J. Weaver, J. Phys. Chem. 100 (1996) 13079.

[10] J. Stöhr, NEXAFS spectroscopy; Springer, 1996.

[11] L. R. Sharpe, W. R. Heineman, R. C. Elder, Chem. Rev. 90 (1990) 705.

[12] A. E. Russell, A. Ross, Chem. Rev. 104 (2004) 4613.

[13] W. S. Yoon, M. Balasubramanian, K. Y. Chung, X. Q. Yang, J. McBreen, C. P. Grey, D. A. Fischer, J. Am. Chem. Soc. 127 (2005) 17479.

[14] T. Herranz, X. Y. Deng, A. Cabot, J. H. Guo, M. Salmeron, J. Phys. Chem. B 113 (2009) 10721.

[15] H. J. Liu, J. H. Guo, Y. D. Yin, A. Augustsson, C. L. Dong, J. Nordgren, C. L. Chang, P. Alivisatos, G. Thornton, D. F. Ogletree, F. G. Requejo, F. de Groot, M. Salmeron, Nano Lett. 7 (2007) 1919.

[16] J. H. Guo, Y. Luo, A. Augustsson, J. E. Rubesnsson, C. Såthe, H. Ågren, H.; H. Siegbahn, J. Nordgren, Phys. Rev. Lett. 89 (2002) 137402.

[17] O. Fuchs, F. Maier, L. Weinhardt, M. Weigand, M. Blum, M. Zharnikov, J. Denlinger, M. Grunze, C. Heske, E. Umbach, Nucl. Instrum. Methods Phys. Res. A 585 (2008) 172.

[18] O. Fuchs, M. Zharnikov, L. Weinhardt, M. Blum, M. Weigand, Y. Zubavichus, M. Bär, F. Maier, J. D. Denlinger, C. Heske, M. Grunze, E. Umbach, Phys. Rev. Lett. 100 (2008) 27801.

[19] K. O. Kvashnina, S. M. Butorin, A. Modin, I. Soroka, M. Marcellini, J. H. Guo, L. Werme, J. Nordgren, J. Phys.: Condens. Matter 19 (2007) 226002.

[20] D. Guay, J. Stewart-Ornstein, X. R. Zhang, A. P. Hitchcock, Anal. Chem. 77 (2005) 3479.

[21] B. Bozzini, L. D’Urzo, A. Giamonvelli, B. Kaulich, M. Kiskinova, M. Prasciolu, A. Tadjeddine, Electrochem. Commun. 10 (2008) 1680.

[22] M. P. Sánchez, M. Barrera, S. González, R. M. Souto, R. C. Salvarezza, A. J. Arvia, Electrochim. Acta 35 (1990) 1337.

[23] M. Drogowska, L. Brossard, H. Ménard, J. Electrochem. Soc. 139 (1992) 39.

[24] M. Magnuson, N. Wassdahl, J. Nordgren, Phys. Rev. B 56 (1997) 12238.

[25] M. Hävecker, A. Knop-Gericke, T. Schedel-Niedrig, R. Schlögl, Angew. Chem. Int. Ed. 37 (1998) 1939. 


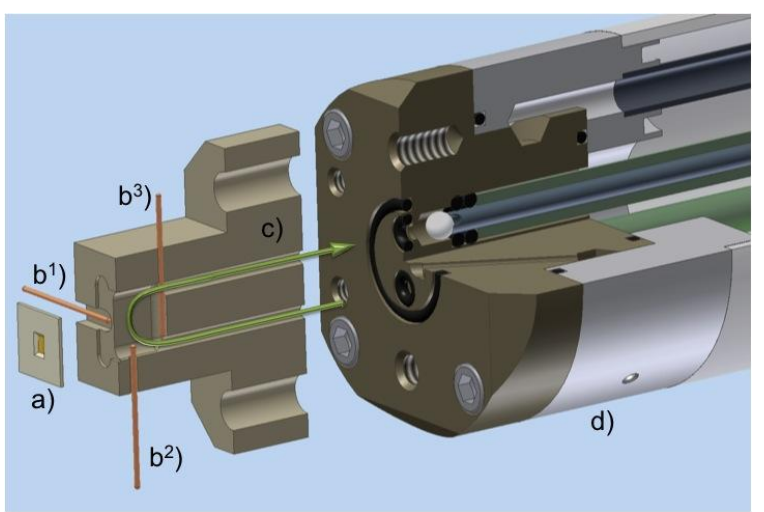

Figure 1. Schematic drawing of the electrochemical cell assembly for in situ x-ray absorption spectroscopy studies. a) $\mathrm{Si}_{3} \mathrm{~N}_{4}$ window, $\mathrm{b}^{1}$ ) electrical connection to $\mathrm{Si}_{3} \mathrm{~N}_{4}$ window (working electrode), $b^{2}$ ) reference electrode, $b^{3}$ ) counter electrode, c) PEEK body, d) support tube assembly. The green arrow indicates the liquid flow.

a)

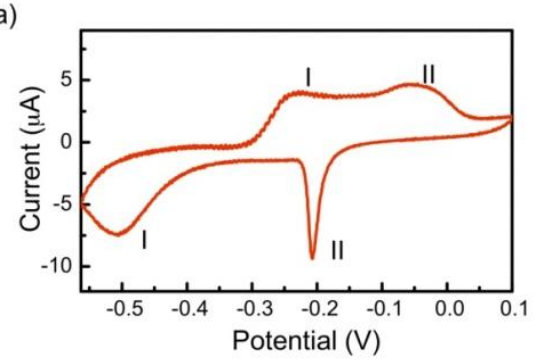

b)

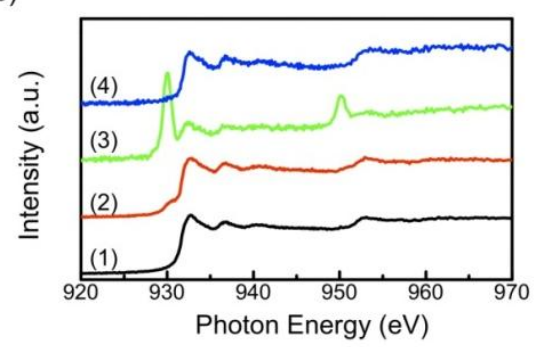

Figure 2. a) Cyclic voltammogram of a $\mathrm{Cu}$ thin film working electrode in $0.1 \mathrm{M} \mathrm{NaHCO}_{3}$ solution at a scan rate of $0.02 \mathrm{Vs}^{-1}$. Pt and $\mathrm{Ag}$ wires were used as counter and pseudo-reference electrodes, respectively. b) Total fluorescence yield XAS of $\mathrm{Cu} \mathrm{L}_{2,3}$-edge. (1) Reference metallic $\mathrm{Cu}$ foil. (2) $\mathrm{Cu}$ thin film ( 300 $\mathrm{nm}$ ) evaporated on the $\mathrm{Si}_{3} \mathrm{~N}_{4}$ membrane (oxidized during transfer in air). Spectra (3) and (4) were recorded after in situ oxidation at nominally $0.2 \mathrm{~V}$ and after reduction at nominally $-0.9 \mathrm{~V}$ in $2 \mathrm{mM}$ $\mathrm{NaHCO}_{3}$ solution, respectively. 

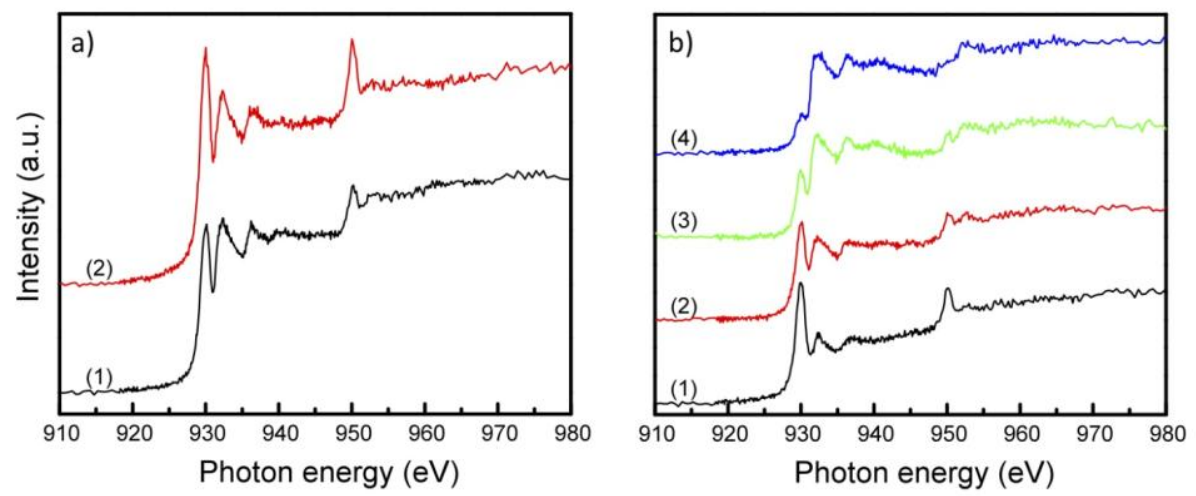

Figure 3. Time evolution of the $\mathrm{Cu} \mathrm{L}_{2,3}$-edge XAS spectra showing the a) oxidation and $b$ ) reduction kinetics in $2 \mathrm{mM} \mathrm{NaHCO}_{3}$ solution at nominal potential of $-0.1 \mathrm{~V}$ and $-1.0 \mathrm{~V}$, respectively. The spectra were collected sequentially with a time difference of approximately 15 minutes. 